\title{
Exploring the Notion of Information: A Proposal for a Multifaced Understanding
}

\author{
Miranda Kajtazi* and Darek M. Haftor \\ " miranda.kajtazi@lnu.se, School of Computer Science, Physics and Mathematics, Linnaeus University, \\ Växjö/Kalmar, Sweden \\ "dh@fek.su.se, School of Business, Stockholm University, Stockholm, Sweden
}

\begin{abstract}
Man's notion of 'information' is essential as it guides human thinking, planning, and consequent actions. Situations such as the Haiti earthquake in 2010, the financial crisis in Greece in 2010, and the oil slick in the Gulf of Mexico in 2010 are just a few instances of constant growing empirical dilemmas in our global society where information plays a central role. The meaning of what information is has clear implications for how we deal with it in our practical lives, which in turn may give rise to situations that we would prefer to be without. In this sense, the notion of information has evidently presented the need to question what it really means and how it dominates the functioning of our global society. To address this fundamental issue of information, two questions are explored and presented in this paper: What notions of information are dominating the scholarly literature? And what are the differences between these notions? To answer these questions, we have conducted a comprehensive literature survey of more than two hundred scholarly publications. Detailed analyses of the content of these publications identified four kinds of forms of information notions. The results show that these four forms present diverse and opposing views of the notion of information, labelled as the 'quartet model of information'. These address different foci, contexts, and challenges. In addition, we propose an alternative and novel understanding of the notion of information, associated with how information functions in our global society. This understanding offers a new perspective intended to address significant needs of the information society.
\end{abstract}

Keywords: Information notion; Information society; Literature survey; Content analysis

Acknowledgement: We would like to thank Professor Anita Mirijamdotter for her valuable comments and support for this research paper.

This paper presents some preliminary findings from an ongoing research into the notion of information and its human, industrial, and societal implications. In this, a novel understanding of information is presented as associated with how information is functioning in our global society. Situations such as natural disasters like the Haiti earthquake in 2010, financial crisis like that of Greece in 2010, and environmental disasters like the oil slick in the Gulf of Mexico in 2010 are just a few instances of constantly growing empirical dilemmas in our global society where information plays a central role. In these and many similar situations a pattern seems to recur in which there is a lack of needed information and/or there is an information overload (e.g. Castells, 1996; 2010).

Not surprisingly, various scholars have given attention to this central and crucial role of information in our human, industrial, and social affairs. Two examples follow. The 1978 Noble Laureate Herbert Simon undertook an evolving approach to construct a new notion of information, which has possible explanations for such situations as those mentioned above. For him, in one way, information is a complex form of human construct; hence, humans' particular reactions can depend largely on information that is available to them (Simon, 1996). Similarly, another Noble Laureate of 2001, George Akerlof, predicted how information has become the main cause of some societal failures, by addressing the economic and political systems that deal with asymmetric information created between interacting actors (Akerlof, 1970). These and other explorations seem to point in the same directions: the meaning of what information is has clear implications for how we deal with it in our practical lives, which in turn may give rise to situations that we would prefer to be without - such as when a surgeon amputates the wrong leg of a patient, because the given information instructed so 
In this way, the notion of information has evidently presented the need to question what it really means and how it dominates the functioning of our global society. Subsequently, the key questions of investigation in this paper are as follows: What notions of information are dominating the scholarly literature? And what are the differences between these notions? To answer these questions, we have conducted an extensive and comprehensive literature review on the notion of 'information'. Results derived from this first present a historical development of many notions of information, mainly evolved during the last century. This has identified that many key notions of information have been proposed, such as information is an 'inward-forming' (e.g. Boland, 1987); information is an 'interpretation' with some attached meaning (e.g. Ackoff, 1989; Bateson, 1972; Checkland \& Scholes, 1990; Langefors, 1993; Mingers, 1995); information is a 'fundamental reality' (e.g. Floridi, 2010; Fuchs, 2008; Hofkirchner, 2009); information is 'physical' (e.g. Brillouin, 1962; Stonier, 1990; 1996); or information is 'transmittable' (e.g. Shannon, 1948), among others. Second, the outcome from these analyses on the information notions has led to a novel categorisation and presentation of four kinds of forms of information (i.e. fundamental, meaningful, quantifiable, transmittable). We introduce a theoretical framework based on these four forms, which we label as the 'quartet model of information'. As a consequence of this new understanding of the diversity of information notions, we were able to develop an alternative and novel notion of information. This study is intended to contribute to a positive management of human, industrial, and social affairs where and when information plays a crucial role.

This paper is structured in the following way: we first introduce the methodological approach that has been employed in this research. Then we present a historical overview of the notions of information. Thereafter we present the quartet model of information notions. Next, we introduce a novel notion of information. We end with a discussion of the implications for theory and practice.

\section{Methodological Approach}

Two types of methodological features have been employed in this study. Firstly, we have conducted a comprehensive literature survey of more than two hundred scholarly publications, starting from the year 1900. The review of these publications was driven by the need to find explicit notions of information. As a result, we have selected around fifty information notions.

Secondly, the analysis conducted on this comprehensive literature review was guided both by Heidegger's necessity of explicit interpretations of universal notions (Heidegger, 1962) and by Husserl's system of propositions that are interlinked and have better overviews of different manifestations in the real world (Husserl, 2001). With the former we intend to lead this enquiry by what is sought: to interpret the notion of information conceptually for what it signifies for the information society. With the latter, we intend to conduct this enquiry with an explorative nature and with a multifaced understanding of the notion of information. This may be more explicitly understood by developing a new notion of information. These two methodologies have driven phenomenological descriptions in our study.

\section{A Historical Overview of the Notion of Information}

The discussion about the notion of information has been present in all scientific disciplines. However, this literature survey identified those discussions as rather diverse and opposing (e.g. Bates, 2006; Bateson, 1972; Boland, 1987; Brier, 1998; 2008; Floridi, 2005; Hofkirchner, 1999; Parker, 1973; Pervez, 2009; Qvortrup, 1993; Rapoport, 1953; Shannon, 1948; Wiener, 1948). Thus, information is viewed as an infinite of its characteristics, such as data or knowledge, signal or communication, symbol or meaning ... (e.g. Bateson, 1972; Boland, 1987; Brier, 2008; Checkland \& Scholes, 1990; Hartley, 1928; Langefors, 1993; Shannon, 1948). Furthermore, these diversities have been used in different fundamental forms of information's very existence, namely: information is physical, biological, psychical, mechanical, social, digital ... (e.g. Bateson, 1972; Bates, 2006; Brier, 1992; 2004; 2008; Floridi, 2010; Maturana \& Varela, 1980; Mingers, 1995; 2001). Above all, information has long been understood as a universal notion (Heidegger, 1962), and it has been given freedom to be used without consensus in different scholarly domains (e.g. Adams, 2003; Floridi, 2005; Losee, 1998; MacKay, 1969). 
In addition, we intend to systematically understand the diversities between information notions that derive from two Cartesian doctrines, which govern the practice of defining information:

- The 'subjective' orientation towards human communication of the meaning of information (Belkin, 1978; Luhmann, 1990).

- The 'objective' orientation towards external physical components of the universe that comprise information (Brillouin, 1962; Landauer, 1991; Stonier, 1996).

Many scholars have devoted effort to distinguishing these two doctrines (Bates, 2006; Brier, 1992; 2008; Capurro \& Hjørland, 2003; Floridi, 2010; Hofkirchner, 2009; Pervez, 2009).

Regardless of the growing awareness of this dilemma, little work has been done to address the understanding of the many differences among the existing notions of information. From previous contributions, we have noticed that they mostly concentrate on defining information through one of this tripartite: 'philosophically' (through philosophy of information, the physical and the semantic nature of information) (e.g. Floridi, 2010; Mingers, 1995; Qvortrup, 1993), 'mathematically' (through information theory, the measurable and quantifiable information) (e.g. Brillouin, 1962; Hartley, 1928; Landauer, 1991; Shannon, 1948), or more 'universally' (through the unified theory of information, the evolutionary information, the dependency on dissipative and living systems) (Fuchs, 2008; Hofkirchner, 1999; 2009). Contrarily, the quartet model of information notions proposed below can help us to unify this presented diversity.

\section{The Quartet Model}

The historical review and analysis of the various information notions conducted here may be summarised in terms of four kinds of forms of information notions, or the quartet model. These four kinds of forms are: information is 'fundamental', information is 'meaningful', information is 'quantifiable', and information is 'transmittable'. All of the notions that are used to build the quartet model belong to the era of investigations from industrial revolution to information society (e.g. Castells, 2010). This presents the era of immense research on bringing the meaning of fundamental notions of our existence into discussions and debates.

Our position is that the proposed quartet model has generated some interesting and useful results as the classification of information notions draws on four initial accounted forms of information. All these notions are based on philosophical implications of the doctrines of objectivism and subjectivism. Thus, the following four forms of the notion of information are introduced:

- 'Information is Fundamental'. These notions are primarily concerned with the concept of information as something that is equal to the basic substances or insubstances of the universe. (Elaborated in Section 3.1.)

- 'Information is Meaningful'. These notions are primarily concerned with knowledge and human capabilities, which are able to interpret and give meaning to something that is or becomes information. (Elaborated in Section 3.2.)

- 'Information is Quantifiable'. These notions are not concerned with whether information is related to the fundamentals or its meaning given by human beings. Rather, they are only concerned with the technical sphere; they are concerned with the finding of technical possibilities to measure information. (Elaborated in Section 3.3.)

- 'Information is Transmittable'. These notions are only concerned with how information is transmittable, possibly in the same quantity, from one point to another. These notions are strongly related to a composition of what would be 'quantifiable information' and 'communicated information communicated to its destination', the latter in terms of human values. (Elaborated in Section 3.4.)

Various scholars have had a rather fascinating look into the notion of information. Their notions have been exclusive for their environments and thoughts (e.g. Bateson, 1972; Fuchs, 2008; Israel \& Perry, 1990; Sebeok \& Danesi, 2000; Shannon, 1948; Wiener, 1948), among many others. Our 
focus is on classifying these different notions of information by restructuring the discussions that compelled no consensus. Other research has explored information that occurs as a companion entity for other essential concerns, in the context of calculations in mathematical theory (e.g. Landauer, 1991; MacKay, 1969; Rapoport, 1953; Shannon, 1948; Wiener, 1948), semantic information (e.g. Bar-Hillel \& Carnap, 1953; Dretske, 1981; Floridi, 2005), information as a form: autopoietic and semiotic (e.g. Bateson, 1972; Brier, 2008; Britz, 2007; Madden, 2004; Maturana \& Varela, 1980; Qvortrup, 1993; Peirce, 1958), and information as meaning (e.g. Bawden, 2007; Boland, 1987; Checkland \& Scholes, 1990; Langefors, 1993).

We use this diversification to distinguish our intention of presenting why there is a need to balance these forms of information, and we argue that the application of each form in our current surroundings is useful for what each signifies.

In reflection to the presented classification of notions, we illustrate below a historical overview of some key authors that have guided us to develop the presented quartet model.

The basis of our enquiry to develop this approach is focused on the classifications as presented in Figure 1. The proposed classification is mainly developed on the basis of practices among scholars who have been subject to diverse scientific influences on defining the notion of information.

We illustrate the application of those selected information notions within this framework by developing some theoretical understandings (contexts, challenges, dimensions). As a result of this development, the tendency has been to re-conceptualise the notion of information. For that, not only has information become significant for someone in its indefinite understandings, but also we consider that information as a notion has become more explicit to everyone in its quartet appearance.

Finally, since we have tackled this dilemma at length, we argue that the quartet as our approach may possibly change the theoretical understanding (of being equivocal) of the notion of information.

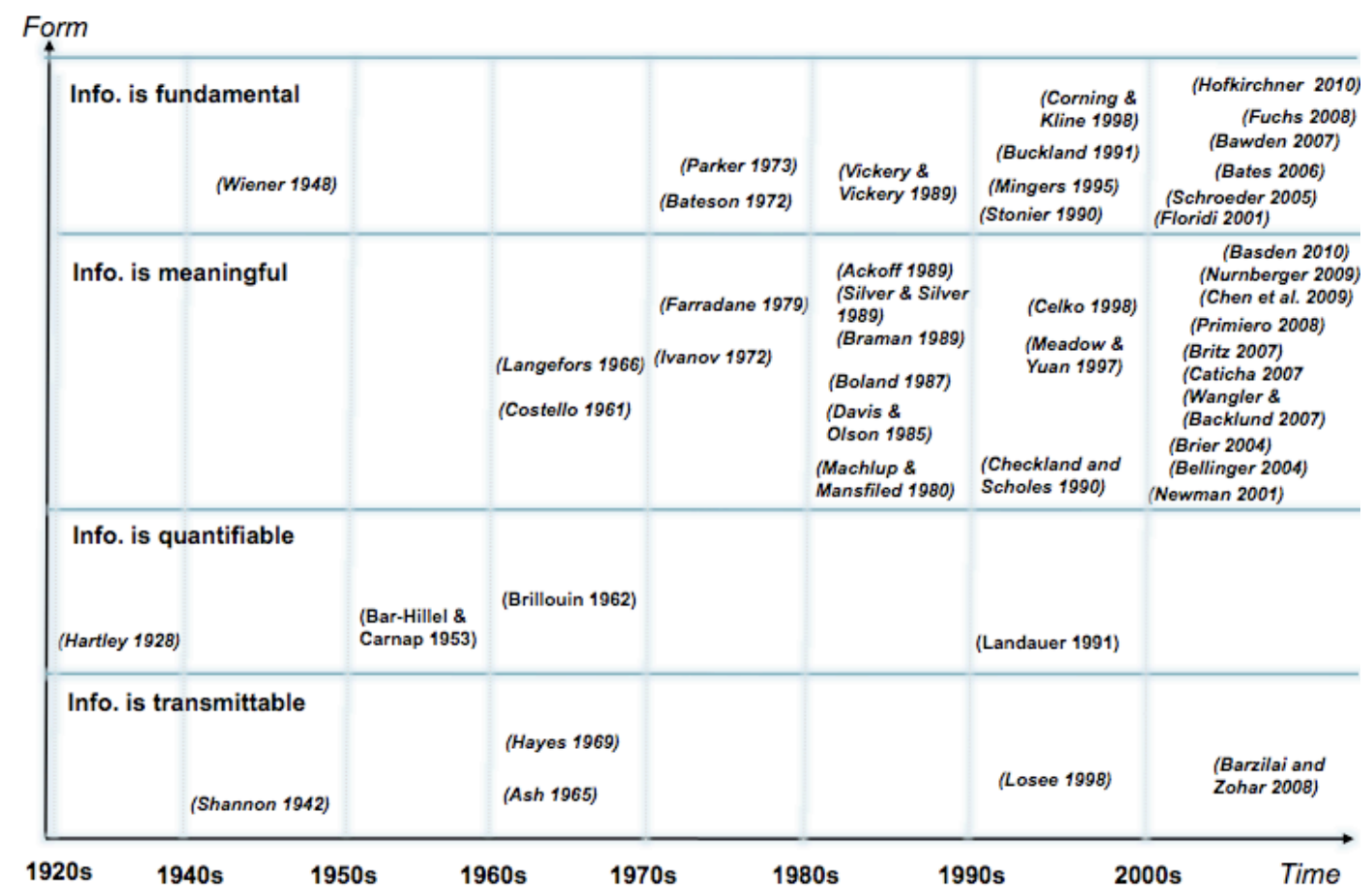

Figure 1: The presentation of the quartet model: historical developments of the notion of information 
The next four sub-sections present an overview of each of these identified forms. Due to limited space, we only mention some key selected notions in each of these forms. To strengthen our overview, we also discuss more specifically one selected notion under each form. In this way, we intend to clarify how such selected notions are related to these four forms.

\subsection{Information is Fundamental}

This kind of information form presents the developments and understandings on the notion of information as being 'fundamental'. Here, information is regarded as one of the essential elements that constitute our world (Floridi, 2003, 2010). There are several independent approaches that tried to explain at least information's role as a constitutive element so far, but not concisely its meaning. Some of these approaches come from the trans-disciplinary influence. They define information in this context: "information is a difference that makes a difference" (Bateson, 1972, p.459); "information is information, not matter and energy" (Wiener, 1948, p.132); "information has arisen as a concept as fundamental and important as 'being', 'knowledge', 'life', 'intelligence', 'meaning', or 'good and evil', all pivotal concepts with which it is interdependent" (Floridi, 2001, p.16); "Information is that part of the process of self-organization that is responsible for generating new features in the system's structure, state or behavior" (Hofkirchner, 2010, p.62); "information is different from meaning. Information is an objective, although abstract, feature of the world in the same way as are physical objects and their properties" (Mingers, 1995, p.295).

Our understanding of this information form is that its constituting notions attempt collectively to conceive of information as being fundamental and independent of anything else that constitutes our world. Furthermore, for this information form, information can be insubstantial, which defines the differences between the substances (the tangible) and the differences between the imperceptible (the intangible). Information can also be considered as an independent complex element for how it comes to existence, how it is interpreted by human context, or how it dissolves in the objective and subjective nature, and how it recurs.

In this regard, for us, perhaps the most profound notion of information, in this category of information being fundamental, is Bateson's proposal that information is a "difference that makes a difference" (Bateson, 1972, p.459). However, a critical question then asks whether this notion is meaningful and elementary, and in practice, this is the preparatory investigation for one to start thinking about what is deeply meant by the notion of information.

For Bateson, the infinity - of the differences - is what truly matters in whatever we experience in this world as information. It is 'us' - the living beings - and it is the 'objects' - the physical entities that in the way 'we' or the 'objects' continually transform (change through time) experience an infinite range of differences. This, according to Bateson (1972), is a journey that is first made possible through hard sciences. Indeed, this is the way in which the basis of our creation, the matter and energy, trigger every chance to experience a difference. Thus far, this has only illustrated the broad nature of the Batesonian philosophy of information. Our question 'what is really meant by these differences of information?' is yet to be explicated. For what is really meant by Bateson's difference, he clearly points out that 'we', or the 'objects', exist around infinite differences, that is, between the 'object' and the 'moon', between 'us' and the 'moon', between the 'object' and the 'us', and so on. Even more, for every 'us' or for every 'object' there are molecules, which have infinite differences between their current locations, past locations, or the locations in which 'we' or the 'objects' might be. Thus for every one of 'us' there is a different way of perceiving information, in fact, very different in terms of how this is conceived for every 'object'. For 'us', it can be from the inside, the sensory input from our mental abilities. It can also be from the outside, in the propagation of light and sound, the matter and energy. Be that as it may, this contrast is not absolute, Bateson points out (1972, p.460). As a matter of fact, this contrast must be mentioned and understood; otherwise it can lead one to problems. If it is necessary to pronounce this, then this is truly the greatest (yet too broad) meaning of the notion of information. 


\subsection{Information is Meaningful}

This form of information presents a growing scholarly orientation in the last three decades. Information here is defined as something that must be interpreted by human-beings. Many of the selected notions derive from diverse areas of research, such as: personal worldviews, individual experiences; human knowing and human management; human social values, and the like. Hence, they define information as: "information equals data plus meaning" (Checkland \& Scholes, 1990, p.303); "information is an inward-forming. It is the change in a person from an encounter with data. It is the change in the knowledge, beliefs, values or behavior of that person" (Boland, 1987, p.363); "information is interpreted data, it is something we get to know, it is knowledge of some sort" (Langefors, 1993, p.111); "information is understood as potential until somebody interprets it" (Brier, 2004, p.629); "information is data that are processed to be useful, providing answers to 'who', 'what', 'where', and 'when' questions" (Ackoff, 1989, p.5); "information-as-expressed-meaning" (Basden, 2010, p.18).

From our understandings, the developments in this area suggest that there has been a broad view on defining information as meaningful (from social aspects to individual aspects), although each of them regards human values as critical, by putting the human understanding and human interpretation as the main source of creating information.

Every scholarly discipline uses the concept of information in a variety of contexts. A critical yet interesting debate on this pattern is introduced by Boland (1987) in his attempt to examine the most crucial issues that concern information systems (Boland, 1987). In particular, he focuses on the issue of how information has become a common dominator. For him, information is a notion which is capable of bringing together the basic elements of our existence simply into a single framework of analysis. His concern, which is to investigate the use of the notion of information in a variety of forms, is due more to its use as a metaphor than to what information is in reality. In this aspect, he argues that there are some central information aspects of our social world. Boland's conception of information has been intruded by the five most popular dictum fantasies of our time. He divided them on the basis of various research initiatives that took the responsibility to define information for their interests - the dictum. In spite of this investigation, for Boland, each of them has failed to realise that the necessary condition of defining information is the interpretive system. In other words, it is the mental state of the human knower. His five identified fantasies were presented in sequence, and his intention was to highlight the focus of each: the removal of the human factor. It is through his accomplishments on research that he identified these fantasies: (i) information is structured data; (ii) an organisation is information; (iii) information is power; (iv) information is intelligence; and $(\mathrm{v})$ information is perfectible.

In all these five forms, Boland intends to remain sceptical of how each utilises information. He purposely refers to them as fantasies, or as imaginative devices that are not capable of describing the reality but can only suggest a possibility. However, his conception of fantasy is related to creativity versus delusion, composed of two faces: the productively imaginative face, and the selfdeluding face (Boland, 1987, p.367). This idea of fantasies is primarily concerned with stressing the intention to remove the human aspect, together with the human action and human meaning. The sequential presentation of the five fantasies is designated to fail, argues Boland, because information is prima facie a human element. Thus, information for him is not structured data. It is not an object with potential to design organisations. It is not an object that possesses intelligence, it does not give or bring power, and it is not perfectible (Boland, 1987, p.370).

As a substitute for the five fantasies, for Boland information is an inward-forming. It can be a part of sense making for human beings and their lived experiences that allow them to understand the world, even if, on the contrary, information could be regarded as an object that does not invoke the necessary meaning of a particular situation within our world but can in fact delude our understandings. 


\subsection{Information is Quantifiable}

It is evident that the era when understandings of this form of the notion of information developed presents the era when technology started to flourish. The understanding of information in the form of being quantifiable comes from the Bell Systems Laboratory, primarily starting with Hartley's notion that "information is a measurable quantity" (Hartley, 1928, p.536). His influence has spread to his research stream; however, the use of the notion of information in his context has since been very weak. Thus, his contribution today is re-interpreted as signals or digital inputs, rather than information. There are very few such notions. Similar notions put the role of information as something tangible, such as "information can have attached measure to it" (Bar-Hillel \& Carnap, 1953, p.149) or "information is physical" (Landauer, 1991, p.23). Indeed, such understandings of information are related to quantum physics and thermodynamics with developments of entropy and negentropy, which are concerned with creation of physical patterns that carry energy and that in turn generate information (Bar-Hillel \& Carnap, 1953; Landauer, 1991).

Here, we purposely elaborate more on the notion first stated by Hartley (1928), to gain a better insight on his view. It is clear that he put effort into trying to attach quantity to information, in terms of the engineering aspect of electrical communications. His understanding of information came to mean something that appears in telegraphic or telephonic forms of communication. His interest was to explore a system's capacity to transmit information signals and symbols, by simply adding some sort of measurable quantity. What is important in this understanding is that Hartley clearly states that information is an elastic term; therefore it is necessary to set up a specific meaning, which addresses his view. Hence, Hartley's intention was to quantify the use of information as symbol representation, which for someone (here putting the human context) would mean something. He says: "in any given communication the sender mentally selects a particular symbol and by some bodily motion, as of his vocal mechanism, causes the attention of the receiver to be directed to that particular symbol' (Hartley, 1928, p.536). Further to this understanding, Hartley explores the human meaning aspects of information (here, he presents a well-elaborated example of how someone would interpret the sentence 'apples are red'), for which he concludes that such an understanding would be of psychological factors. Thus, for him, it is desirable to eliminate such implications while establishing a measure of information in terms of pure physical quantities.

\subsection{Information is Transmittable}

The last form of information identified in this literature survey presents the most debated research. This form also comes from the Bell Systems Laboratory developments.

It starts from the pioneering work of Shannon and Weaver (1949) in the late 1940s, when Shannon first argued that "information is transmittable ... the fundamental problem of communication is that of reproducing at one point, either exactly or approximately, a message selected at another point" (Shannon, 1948, p.379). In more detail, they introduce the notion of entropy in relation to the notion of information, but very vaguely defined.

Information regarded as transmittable comes from the aspect of transmission of information with noisy communication, which would largely affect the final destination of information (here, Shannon means the final input to a human being). For Shannon and Weaver, the transmission of information that conveys some message may be of importance for humans. This is what they had in mind when they stated: "the destination of information transmission can be a person or it can be a thing for whom the message is intended" (Shannon, 1948, p.2).

Nevertheless, Shannon and Weaver have been unclear on why and how they put into the context the human understanding of transmitted information, because for them the semantic aspects remain irrelevant to engineering problems. However, entropy is the fundament of information, defined via the mathematical theory of communication, primarily considering Boltzmann's meaning of entropy. This form of entropy, for Shannon, is put in terms of improbability of inspecting noise in communication of information, implying that meaning will be disordered at its final destination - the human being. Hence, this differs from thermodynamic perspectives of Boltzmann's entropy, which 
is concerned with changes in physical energy. In spite of this, Shannon states: "it is important to emphasize, at the start, that we are not concerned with the meaning or the truth of messages; semantics lies outside the scope of mathematical information theory" (Shannon, 1948, p.2).

This controversy led to immense discussions and debates from trans-disciplinary views.

\section{Introducing an Alternative Understanding of the Notion of Information}

So, what is really information? Can we contextualise information as being fundamental? Is information really meaningful? Does it exist out-there, without attaching to it the human interpretation? Or is it necessary to bring a complete new reductionist approach, minimising its role as being quantifiable or transmittable? And, how is it possible to have information about information?

The preliminary results of this ongoing research have provided us with an alternative understanding of the notion of information. The diversity of notions of information presents information as a universal notion - in the sense of Heidegger's understanding - and as a complex element - that which Akerlof (1970) and Simon (1996) indicated.

Our understanding of the notion of information is rooted in the quartet approach. Moreover, we intend to give critical value to the notion of information by associating it with its central functioning in our global society. Thus, we propose to understand 'information' as: 'representation of principles that guide humans' understanding to utilise the meaning of data in handling their needs in a particular situation at a particular moment in time'. Insofar as information is presented here simply as an entity of our existence, it clearly requires that there shall be a right way to access this entity, which must be obtained and secured in advance for the human well-being. Information here lies across the intended meaning and the conveyed meaning, formed of principles that guide choosing, conceiving, or accessing information. This new understanding of information is a concrete proposal that relates to the subjective nature of our existence as much as it relates to our objective surroundings, and thereby attempts to bridge the Cartesian subject-object gap dominating the various notions of information. Our intention is to explore the role of information by offsetting the principles that determine how human interpretation has come to play a critical role in situations where information becomes the main source of cause. The implication of this understanding is that information is an independent factor that plays a central role in our cognitive and material world.

\section{Discussion}

This paper presents a study where some of the most central notions of information are presented. While the various previous contributions to the understanding of information have already given some insights and also some new ideas regarding the meaning of information, the research presented here suggests that the notion of information is still an elusive concept, yet it also seems to be one of the most central concepts of our present civilisation; "indeed, as an explicandum, it can be associated with several explanations" (Bar-Hillel \& Carnap, 1953, p.9); "information is said to remain vague, while the confusion continues to reign" (Britz, 2007, p.33); "information is still a tricky concept" (Qvortrup, 1993, p.3); and "information is a popular term that has complicated its theoretical definitions" (Pervez, 2009, p.1).

Certainly, these abovementioned views present the only unified understanding of the notion of information, and thus in this context they have consensus. Nevertheless, these references are just samples taken from the literature. Almost every contribution that has taken for granted the notion of information introduces the reader to how this notion is thoughtfully regarded as equivocal. Now this remains critical for this research. Yet, and apart of finding ourselves in that consensus, we have presented our view of the notion of information in the quartet of its forms. Furthermore, we have demonstrated the application of our theoretical framework by introducing an alternative understanding of this notion. The latter is a proposal which may not have precisely given a specific understanding of the notion of information - that would rather be an unfruitful reduction. This has rather given a generic understanding of the most basic information forms, 'the quartet', which we brought together in the context of this understanding. 


\subsection{Implications for Theory and Practice}

Our theoretical framework - the quartet approach - can be used to further develop theoretical and meta-theoretical views, in regard to our analyses and results, together with all other developments in this area of research. We focused on previous contributions that have dealt with the notion of information explicitly. This, the response to our research questions is to theorise about the role of the notion of information in its diversity. Subsequently, this requires specifying how information is understood. We have argued that our understanding of the nature of information helps to better specify the four forms of the quartet model. There are some important differences between the four forms of information presented in the quartet model. This contribution indicates a more concrete theoretical understanding, which is likely to significantly reform the ideas behind the notion of information in the near future. Even if this approach has common features with what has been said before, it differs in some important ways. The notion of information is understood in four ways. Based on this, we conceptualise the relationship between each of these forms as dynamic and intertwined, where, for example, the act of sharing information requires the use of the quartet approach to complete a sequence of activities that give meaning to information, as indicated in each of the information forms of the quartet.

The presented quartet model and the introduced novel understanding of the notion of information also have important implications for its practice in the information society. The results provide an analytical tool for human beings, who many times become the victims of unwanted causes and consequences of societal failures and fatalities. To follow up on one of our situations presented in the introduction, that of the recent financial crisis in Greece, information is regarded as the source of generating such a crisis. In our understanding, if information had been utilised appropriately, and if information had been interpreted correctly for the needs of human beings, it would have been unnecessary for the bailout to occur, especially now in the time when the current global crisis is creating extreme depression in our economic and societal environments.

\section{Summary}

Information, understood as 'representation of principles that guide humans' understanding to utilise the meaning of data in handling their needs in a particular situation at a particular moment in time' shows its importance in empirical dilemmas when societal failures or fatalities caused by the lack of needed information lead to unwanted consequences: the Haiti earthquake in 2010, the Greece Crisis 2010, or the oil slick in the Gulf of Mexico in 2010. In this paper we present a literature survey of scholarly research that explicitly addresses the need to understand and/or define the notion of information. The results show that the notion of information is highly diversified, ill-defined, and with no consensus, which presents a typical universal notion that is hard to understand. Thus, the research presented in this paper intends to classify this diversity by introducing four forms of the notion of information, labelled as the "quartet model of information". Moreover, this classification introduces an alternative and novel understanding of the notion of information, still in its infancy, but regarded as highly relevant in empirical dilemmas. This calls for joining the efforts and aiming to shift the notion of information to a whole new perspective by addressing significant needs of the information society.

\section{References}

Adams, F. (2003). The informational turn in philosophy. Minds and Machines, 13(4), 471-501.

Ackoff, R. L. (1989). From data to wisdom. Journal of Applied Systems Analysis, 16, 3-9.

Akerlof, G. (1970). The market for 'lemons': Quality uncertainty and the market mechanism. Quarterly Journal of Economics, 84(3), 488-500.

Basden, A. (2010). On using spheres of meaning to define and dignify the IS discipline. International Journal of Information Management, 30(1), 13-20.

Bar-Hillel, Y., \& Carnap, R. (1953). Semantic information. British Journal of Science, 4, 147-157.

Bateson, G. (1972). Steps to an ecology of mind. New York: Ballantine Books. 
Bates, M. J. (2006). Fundamental forms of information. Journal of the American Society for Information Science and Technology, 57(8), 1033-1045.

Bawden, D. (2007). Information as self-organized complexity: A unifying viewpoint. Proceedings from the Sixth International Conference on Conceptions of Library and Information Science: "Featuring the Future". Retrieved from http://informationr.net/ir/12-4/colis/colis31.html.

Belkin, N. J. (1978). Information concepts for information science. Journal of Documentation, 34(1), 55-85.

Boland, R. J. (1987). The in-formation of information Systems. In R. J. Boland \& R. A. Hirscheim (Eds.), Critical Issues in Information Systems Research (pp. 364-379). New York: John Wiley \& Sons.

Brier, S. (1992). Information and consciousness: A critique of the mechanistic concept of information. Cybernetics and Human Knowing, 1(2/3), 1-24.

Brier, S. (1998). Cybersemiotics: a transdisciplinary framework for information studies. BioSystems, 46, $185-191$.

Brier, S. (2004). Cybersemiotics and the problems of the information-processing paradigm as a candidate for a unified science of information behind library information science. Library Trends, 52(3), 629-658.

Brier, S. (2008). Cybersemiotics: Why information is not enough! Toronto: University of Toronto Press.

Brillouin, L. (1962). Science and information theory. New York: Academic Press.

Britz, J. J. (2007). Definition of information. Research Report. South Africa: University of Pretoria Publishing.

Capurro, R., \& Hjørland, B. (2003). The concept of information. In B. Cronin (Ed.), The Annual Review of Information Science and Technology, 37, 343-411.

Castells, M. (1996). The rise of the network society. Malden: Basil Blackwell.

Castells, M. (2010). The power of identity: The information age: Economy, society and culture. Chichester: Wiley-Blackwell.

Checkland, P., \& Scholes, J. (1990). Soft systems methodology in action. Chichester: John Wiley and Sons.

Dretske, F. I. (1981). Knowledge and the flow of information. Oxford: Blackwell.

Floridi, L. (2001). What is the philosophy of information? Metaphilosophy, 33(1/2), 123-145.

Floridi, L. (2003). Two approaches to the philosophy of information. Minds and Machines, 13(4), 459-469.

Floridi, L. (2005). Is information meaningful data? Philosophy and Phenomenological Research, 70, 351-370.

Floridi, L. (2010). Information: A Very Short Introduction. Oxford: Oxford University Press.

Hofkirchner, W., Fuchs, C. \& Klauninger, B. (2005). Informational universe: A praxo-onto-epistemological approach. In E, Martikainen (Ed.), Human approaches to the universe: Interdisciplinary studies (pp. 75-94). Finland: Bookstore Tiedekirja.

Fuchs, C.. (2008). Towards a critical theory of information. In D. Nafria, J. M. Salto \& A. Franciso (Eds.), Qué es Información? (What is Information?). Proceedings from the First International meeting of Experts in Information Theories. An Interdisciplinary Approach. León: Universidad de León.

Hartley, R. V. L. (1928). Transmission of Information. Bell System Technical Journal, 7, 335-363.

Heidegger, M. (1962). Being and time. London: Harper \& Row.

Hofkirchner, W. (Ed.) (1999). The quest for a unified theory of information. Proceedings from the Second International Conference on the Foundations of Information Science. Amsterdam: Gordon and Breach.

Hofkirchner, W. (2009). A unified theory of information: An outline. Creative Commons License.

Hofkirchner, W. (2010). Twenty questions about a unified theory of information: A short exploration into information from a complex systems view. Litchfield Park AZ: Emergent Publications.

Husserl, E. (2001). Logical investigations. Volume 1. London: Routledge.

Israel, D., \& Perry, J. (1990). What is information? In P. Hanson (Ed.), Information, language and cognition (pp. 1-19). Vancouver, BC: University of British Columbia Press.

Landauer, R. (1991). Information is physical. Physics Today, 44, 23-29.

Langefors, B. (1993). Essays on infology: Summing up and planning for the Future. In B. Dahlbom (Ed.), Gothenburg Studies in Information Systems (Report 5), Gothenburg: University of Gothenburg Press.

Losee, R. M. (1998). A discipline independent definition of information. Journal of the American Society for Information Science, 48(3), 254-269.

Luhmann, N. (1990). Essays on self-references. New York: Columbia University Press.

MacKay, D. M. (1969). Information, mechanism and meaning. Cambridge, MA: MIT Press.

Madden, A. D. (2004). Evolution and information. Journal of Documentation, 60(1), 9-23.

Maturana, H. R., \& Varela, F. J. (1980). Autopoiesis and cognition. Dordrecht: Reidel.

Mingers, J. C. (1995). Information and meaning: Foundations for an intersubjective account. Information Systems Journal, $5,285-306$.

Mingers, J. (2001). Embodying information systems: the contribution of phenomenology. Information and Organisation, 11, 103-128.

Parker, E. (1973). Information and society. Proceedings from the Conference on the Needs of Occupational, Ethnic, and other Groups in the United States (pp. 9-50). USA: Library and Information Needs for the Nation.

Peirce, C. S. (1931-58). The Collected Papers (edited by C. Hartshorne \& P. Weiss (Volumes 1-6) \& A. Burks (Volumes 78) Cambridge MA: Harvard University Press.

Pervez A. (2009). Information as form. tripleC: Cognition, Communication, Co-operation, 7(1), 1-11.

Qvortrup L. (1993). The controversy over the concept of information. An overview and a selected and annotated bibliography. Cybernetics \& Human Knowing, 1(4), 3-24.

Rapoport A. (1953). What is information? Etc., 10, 247-260.

Stonier, T. (1990). Information and the internal structure of the universe: An exploration into information physics. London: Springer.

Stonier, T. (1996). Information as a basic property of the universe. Bio Systems, 38(2-3), 135-140.

Sebeok, Th. A., \& Danesi, M. (2000). The forms of meaning: Modeling systems theory and semiotic analysis. Berlin: de Gruyter. 
Shannon, C. E. A. (1948). Mathematical theory of communication. Bell System Technical Journal, 27, 379-423 \& 623-56. Shannon, C., \& Weaver, W. (1949). The mathematical theory of communication. Illinois: The University of Illinois Press. Simon, H. A. (1996). The sciences of the artificial. Cambridge: MIT Press.

Wiener, N. (1948). Cybernetics or communication and control in the animal and the machine. Cambridge: MIT Press.

\section{About the Author}

Miranda Kajtazi

Miranda Kajtazi is a PhD candidate in Informatics, at the School of Computer Science, Physics and Mathematics, at Linnaeus University in Sweden. She received a Master's degree in Computer Science from Växjö University and a Bachelor's degree in Computer Science from South East European University. Her research interest concerns one of the most crucial resources of our human and social affairs: information. Thus, Miranda explores the interplay of social dynamics and technology by focusing on the causes and consequences of information inadequacy in our global society. She has also worked in industry as a software engineer and a database administrator.

Darek M. Haftor

Darek M. Haftor, PhD (prev. Darek M. Eriksson), is currently an associate professor at the Stockholm University School of Business, Stockholm, Sweden. He has studied the sciences and arts at various universities in Europe and North America, and received his doctorate in Industrial Organization at Chalmers University of Technology, Sweden. He has spent fifteen years in various managerial positions in the private industry sector, and has worked in Europe and the Middle East. Previously, he has held several academic positions in Sweden, including at the Mid Sweden University, the Luleå University of Technology, and the Linnaeus University, where he is currently affiliated as a senior researcher. Darek is now mainly occupied with research and teaching, and is also the Director of Executive Education at the Stockholm University School of Business. His research addresses two main frontiers: the structure and dynamics of information-based organisations and their operations, and the normative conditions inherent in the design, development, and change of any human affairs. 